\title{
Revisão de Triorla Parks e descrição de uma espécie nova, enfatizando o valor sistemático da espermateca (Diptera, Asilidae)
}

\author{
Denise Medeiros Pamplona ${ }^{1}$ \\ Carlos Cesar de Cima Aires ${ }^{1}$
}

\begin{abstract}
Revision of Triorla Parks and description of a new species enphasizing the systematic value of the spermatheca. (Diptera, Asilidae). The redescription of Triorla interrupta (Macquart, 1834) and T. striola (Fabricius, 1805) and the description of $T$. parastriola sp.n. are presented with illustrations of the abdomens, male and female terminalia and the spermathecae.

KEY WORDS. Diptera, Asilidae, Triorla Parks, spermatheca, taxonomy
\end{abstract}

Até o momento, Triorla Parks, 1968 incluía, na região neotropical, duas espécies T. interrupta (Macquart, 1834) e T. striola (Fabricius, 1805). PARKS (1968) fez uma diagnose para Triorla incluindo Asilus interruptus (espécie-tipo), e Dasypogon striola. A distinção das espécies foi realizada usando apenas como caracteres a terminália masculina e a coloração dos tergitos VI e VII da fềmea. No presente trabalho é feita redescrição das duas espécies conhecidas, utilizando quetotaxia da parafaciália e parafrontalia e morfologia das espermatecas. A metodologia utilizada para dissecção da espermateca e a nomenclatura seguiram ARTIGAS (1971). Este autor foi o primeiro a estudar e descrever as espermatecas de Asilidae, que demonstraram grande valor como caráter sistemático e de importância na análise filogenética. Posteriormente ARTIGAS \& PAPAVERO (1988a,b,c) utilizaram tal caráter em estudos dos gêneros de algumas subfamílias. No presente estudo, está sendo utilizado este caráter em nível de espécie. Para redescrição das espécies de Triorla Parks, 1968 foi utilizado material do Museu Nacional, Rio de Janeiro (MNRJ) e Museu de Zoologia de São Paulo (MZSP).

\section{Triorla Parks, 1968}

Triorla Parks, 1968: 175. - Martin \& Papavero, 1970: 69. - Papavero, 1973: 237. - Fisher \& Hespenheide, 1992: 616.

Pilosidade genal e pós-genal ("barba") branca, com ramificações secundárias, exceto as situadas mais próximo do olho; calosidade facial e parafaciália com cerdas; metade inferior da parafrontalia com cerdas; cerdas pós-oculares presentes.

1) Museu Nacional, Universidade Federal do Rio de Janeiro. Quinta da Boa Vista, São Cristóvão, 20940-040 Rio de Janeiro Rio de Janeiro, Brasil.

E-mail: pamplona@acd.ufrj.br 
Mesonoto castanho-escuro com polinosidade prateada lateralmente; dorsalmente, no disco, pequena faixa clara no terço anterior entre duas outras longas mais escuras; cerdas umeral, pós-umeral e pré-sutural ausentes; duas notopleurais, uma supra-alar, uma intra-alar, duas dorso-centrais e uma acrostical; calo pós-alar com cerdas; escutelo com cerdas látero-apicais súpero dirigidas; anepisterno no terço posterior recoberto de cerdas finas e borda inferior do basilar posterior com cerdas agrupadas; catepisterno e anepímero sem cerdas; esclerito sub-alar com tufo de pêlos. Coxas: face anterior com cerdas, face posterior nua; fêmures recobertos com cerdas; metade superior castanho-avermelhada e metade inferior negra; tíbias de cor semelhante aos fêmures; face ântero-dorsal, na metade apical, com ctenídeo dourado denso e curto; coxa III, face anterior com cerdas curtas; trocânter, na face posterior com cerdas.

Abdome com coloração geral castanho-avermelhada ou negra, com algumas áreas laterais com polinosidade prateada intensa. Segmento I, com cerdas negras lateralmente.

Apódema do edeago em forma de raquete e distifalo trífido e estreito.

Espermateca com três cápsulas ovóides sem canalículos glandulares; ductos capsulares longos, de mesmo tamanho e sem canalículos glandulares, ducto comum bem visível e furca bem desenvolvida.

\section{Triorla parastriola sp.n.}

Figs 1, 2, 7, 8, 11, 14

Holótipo macho. Etiquetado: Surumu, Roraima/IX.1966/M. Alvarenga \&/ F.M. Oliveira Col.; [etiqueta pequena]; HOLOTIPO [etiqueta vermelha]; Triorla parastriola Pamplona \& Aires [MZSP].

Macho. Comprimento: 1,8-2,0 mm.

Coloração geral castanho-escura.

Cabeça. Probóscida negra (castanha no $1 / 4$ basal), nos dois terços basais da face ventral, com pilosidade branca cerca da metade do comprimento da probóscida; palpo castanho, com cerdas apicais, em geral maiores que o comprimento deste; na metade basal da face ventral, com pilosidade branca; pilosidade genal e pós-genal ("barba") branca, maior quanto mais próxima da prosbóscida, com ramificações secundárias, exceto as situadas mais próximo do olho; calosidade facial castanha com polinosidade dourada, com cerdas amarelas ântero-dirigidas; parafaciália com metade inferior castanho-escura, com pouca polinosidade dourada, com três cerdas negras; metade superior semelhante à calosidade facial, nua ou com poucos pelos brancos próximos à antena; escapo tão longo quanto o flagelo, pedicelo menor, ambos castanho-claros, com pêlos amarelados; flagelo castanho escuro menor 1,6 a 1,7 vezes que o estilo; parafrontalia e frontalia castanhas com polinosidade dourada; metade inferior da parafrontalia com cerca de duas a três cerdas negras (as duas anteriores maiores e acompanhadas de pêlos brancos); frontalia com uma mancha castanho-escura entre os ocelos e as antenas; cerca de sete a oito cerdas pós-oculares negras e amareladas, acompanhadas de pêlos esbranquiçados; lateralmente, na altura da antena, cerca de seis a oito cerdas pós-oculares amarelas. 

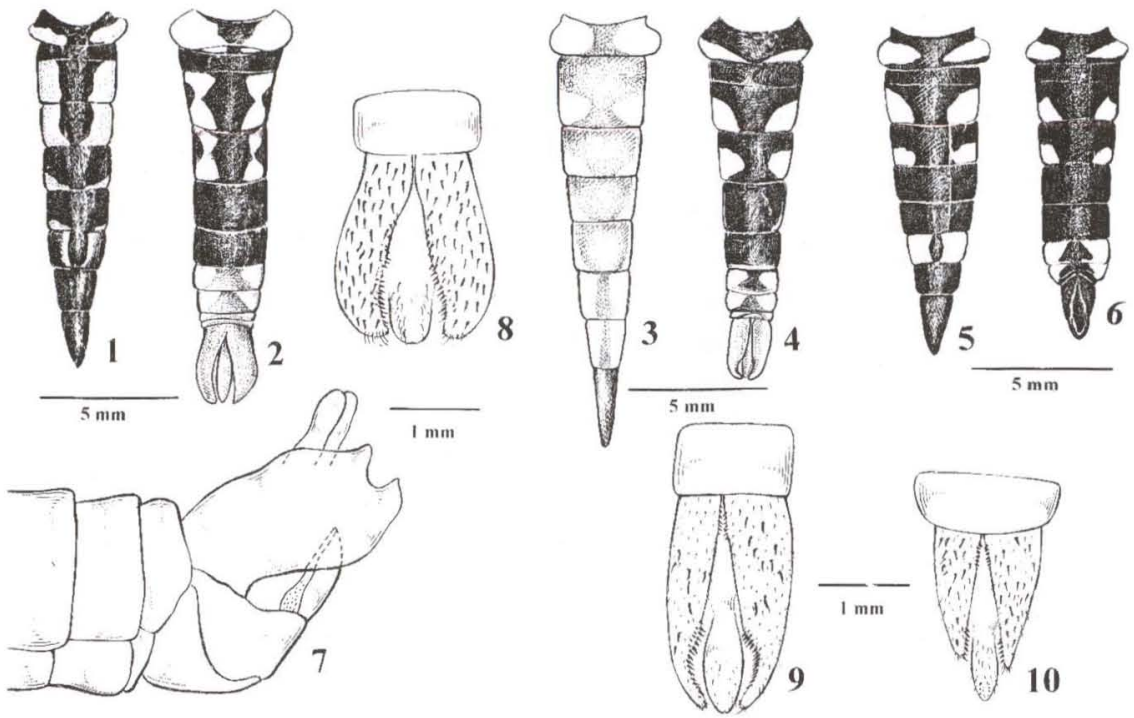

Figs 1-10. (1-6) Abdomes, vista dorsal. (1) Triorla parastriola, fêmea; (2) Idem, macho; (3) T. interrupta fêmea; (4) Idem, macho; (5) T. striola, fêmea; (6) Idem, macho. (7-10) Terminália do macho: (7) vista lateral; (8-10) vista dorsal. (7-8) Triorla parastriola; (9) T. interrupta; (10) T. striola.

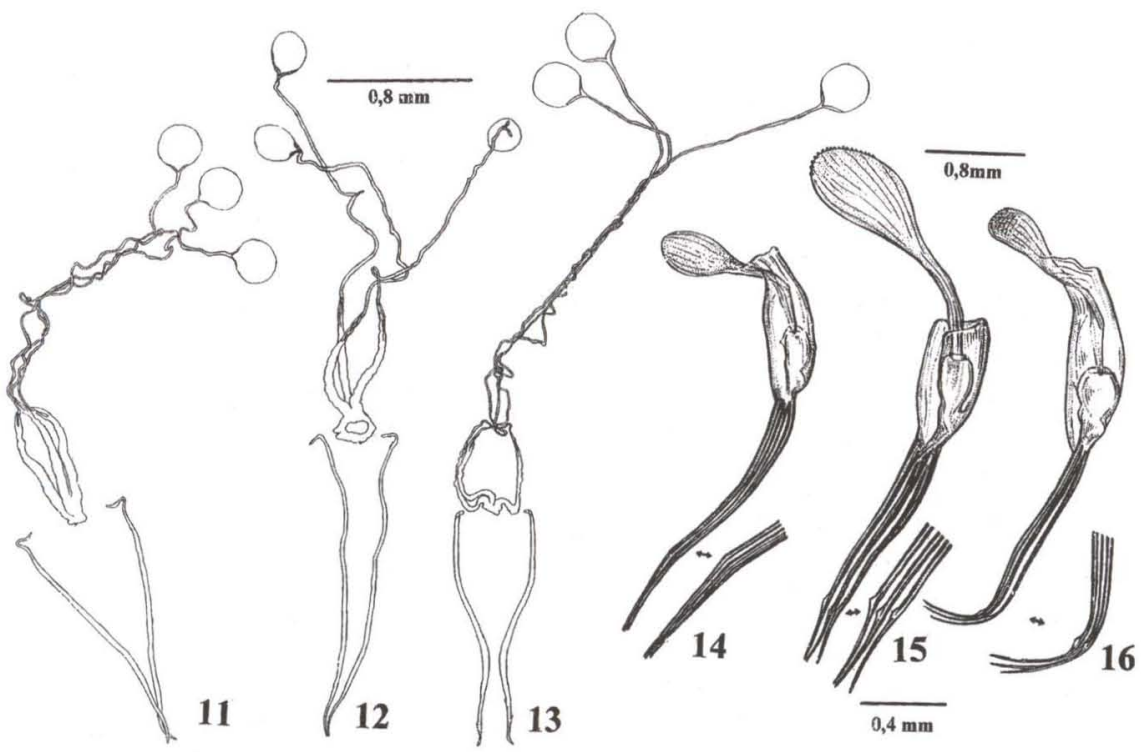

Figs 11-16. (11-13) Espermatecas. (11) Triorla parastriola; (12) T. interrupta; (13) T. striola. (14-16) Complexo fálico. (14) Triorla parastriola; (15) T. interrupta; (16) T. striola. 
Tórax. Esclerito cervical recoberto de pilosidade branca com ramificações secundárias; pronoto castanho com polinosidade prateada mais intensa lateralmente; margem anterior do pronoto com cerca de seis cerdas amarelas, lateralmente recoberto de pêlos brancos; mesonoto com coloração castanho-escura, polinosidade prateada lateralmente de intensidade variada; dorsalmente, no disco, aparece uma pequena faixa clara no terço anterior entre duas outras longas mais escuras; cerda umeral, pós-umeral e pré-sutural ausentes; duas cerdas notopleurais, uma supra-alar, uma intra-alar, duas dorsocentrais e uma acrostical todas negras; calo pós-alar revestido de pêlos amarelos que se continuam na face súpero-anterior da parede pós-alar. Nesta parede, abaixo dos pêlos, com tufo de cílios mais curtos e mais finos amarelados. Calo pós-alar com duas cerdas negras e uma ou duas cerdas pequenas localizadas anteriormente; escutelo basalmente com polinosidade dourada mais intensa, com cerca de quatro a cinco pares de cerdas negras e às vezes algumas amarelas látero-apicais súpero-dirigidas misturadas com raros pêlos negros; propleura no terço anterior com pêlos brancos e posteriormente nua; anepisterno no terço posterior recoberto de cerdas negras finas e borda inferior do basilar posterior com cerca de cinco a sete cerdas negras agrupadas; catepisterno sem cerdas, somente alguns pêlos brancos; anepímero sem cerdas, apenas com pêlos brancos, pouco menores que os do catepisterno, concentrados no disco; esclerito sub-alar com tufo de pêlos, na maioria brancos, medindo cerca da largura do esclerito; catapímero nu; meron nu com uma mancha castanho-escura; catatergito com a metade anterior recoberta de pêlos semelhantes aos do anepímero e no disco com uma fileira de cerdas negras com cerca do tamanho do halter que não se continuam no metanepisterno e metacatepisterno; mas, quando presentes, cerdas bem finas amareladas ou transparentes; halter castanho-claro com cabeça escurecida. Coxa anterior castanha com polinosidade prateada, face anterior com cerdas amarelas e brancas e com uma ou duas cerdas negras, face posterior nua; fêmur na metade superior da face anterior, face dorsal e metade superior da face posterior de cor castanha-avermelhada; metade inferior da face anterior, face ventral e metade inferior da face posterior negra; fềmur revestido por pêlos de fundo amarelos e pêlos negros maiores recobrindo a face dorsal; ântero-ventral, ventral e póstero-ventral com pêlos brancos finos e longos, de ápice em gancho, maiores na metade basal; tíbia de cor semelhante ao fềmur; face dorsal com três a quatro cerdas negras no terço médio; face ântero-dorsal com uma cerda negra basal maior que as demais; face ântero-ventral, na metade apical, com ctenídeo dourado denso e curto que se continua até o segundo tarsômero; face ventral com cerdas longas três vezes maiores que as demais; face ventral com muitos pêlos longos na sua maioria brancos; cerca de oito fortes cerdas negras no ápice distribuídas nas várias faces; tarso de cor e pêlos de mesma posição que a tíbia, primeiro tarsômero com cerca do dobro do tamanho de cada um dos outros; puvilos amarelados com duas listras centrais. Coxa mediana de cor semelhante à anterior, face anterior com quatro cerdas negras, com outras amarelas e tufo menor, acompanhadas de tufo de pêlos brancos, face posterior nua; fêmur de cor semelhante ao anterior; face anterior com três cerdas negras nos terços basal, mediano e apical, face ântero-ventral com cinco cerdas negras, face ventral com três cerdas negras e 
tufo de pêlos amarelos basais, face póstero-dorsal a dorsal com duas cerdas negras oblíquas; tíbia com uma cerda negra mais ou menos sub-mediana nas faces dorsal, ântero-dorsal, ântero-ventral e ventral; faces dorsal e ântero-dorsal com uma cerda no terço médio; face ântero-ventral com uma cerda negra basal; face póstero-ventral com duas cerdas basais e uma pré-apical; face ventral com pêlos longos brancos; tarso mediano igual ao anterior. Coxa posterior, face anterior com duas a três cerdas negras e curtas; trocânter, face posterior com cerca de três cerdas; fêmur na face ântero-dorsal com cerca de duas a três cerdas medianas; face ântero-ventral com fileira com cerca de cinco a seis cerdas negras; face póstero-ventral com cerca de duas a três cerdas basais; face ventral com uma cerda basal e pêlos brancos menores que os dos fêmures anteriores; face dorsal com duas cerdas paralelas pré-apicais; face ântero-dorsal e dorsal com duas cerdas pré-apicais próximas e paralelas; face ventral e ântero-ventral com duas cerdas basais, uma ventral e outra ântero-ventral; tíbia face ântero-ventral com duas cerdas na metade apical, face ântero-dorsal com uma cerda, no terço basal, uma no terço médio e apical; face dorsal com uma cerda basal, duas medianas e uma no terço apical, face ventral recoberta de pêlos brancos e densos; primeiro tarsômero com longos pêlos brancos.

Abdome (Figs 2, 7, 8). Coloração geral negra com áreas laterais com polinosidade prateada intensa. Segmento I, lateralmente, com cerca de duas a quatro cerdas negras entre pêlos amarelados. Segmentos II-III com pêlos (nos machos maiores que nas fêmeas), na maioria brancos, longos e situados nas áreas de polinosidade. O restante dos segmentos abdominais com pêlos de fundo negros e curtos. Terminália masculina com ápice do epândrio curvo distalmente; epândrio com aproximadamente a mesma largura em toda a sua extensão; predominância de cerdas fortes; presença de espinhos na margem interior, no 2/3 distal. Edeago (Figs 14) com apódema do edeago sem espinhos e distifalo sem espessamento.

Fêmea (Figs 1, 11) Comprimento: 1,8-2,0 $\mathrm{mm}$, difere do macho pelas características abaixo.

Parafaciália, com uma ou duas cerdas ou, ainda, ausente; metade inferior da parafrontália com uma cerda negra; cerca de 7 a 8 cerdas pós-oculares todas amareladas acompanhadas de pêlos esbraquiçados; vista ântero-ventral, ventral e póstero-ventral do fêmur anterior com pêlos ralos e curtos; face ventral da tíbia anterior com pêlos ralos e curtos; face anterior da coxa média com uma cerda negra; fêmur médio na face anterior com uma cerda negra, nos terços basal, médio e apical; face ântero-ventral com uma, duas e uma cerdas negras, nos terços basal, médio e apical respectivamente; face ventral com cinco cerdas na metade basal; face ventral da tíbia mediana com pêlos espaçados e curtos; face póstero-ventral do fêmur posterior com uma cerda; segmentos II-III do abdome com pêlos curtos.

Espermateca com furca aproximadamente 1,5 vezes menor que o ducto capsular (Fig. 11).

Material examinado. Parátipos. BRAsil, Roraima: Surumu, 7 machos e 3 fềmeas, IX.1966, M. Alvarenga \& F.M. Oliveira leg. (MZSP). 


\section{Triorla interrupta (Macquart, 1834)}

Figs $3,4,9,12,15$

Asilus interruptus Macquart, 1834: 310.

Erax maculatus Macquart, 1838: 111. - Macquart, 1839: 227.

Erax lateralis Macquart, 1838: 116. - Macquart, 1839: 232.

Erax ambiguus Macquart, 1846: 212. - Macquart, 1846: 84.

Erax concolor Walker, 1851: 130.

Asilus perrumpeus Walker, 1860: 283.

Erax villosus Bellardi, 1861: 149 (49).

Macho difere da espécie nova no que segue abaixo.

Coloração geral castanho-clara.

Cabeça. Calosidade facial com cerdas negras, quando presentes, formando um semi-círculo, cerdas amarelas ou brancas ântero-dirigidas, nunca terminando no meio do semi-círculo e cerdas brancas menores intercaladas com as amarelas; parafaciália com nenhuma ou apenas uma cerda negra; metade inferior da parafrontalia com cerca de seis cerdas brancas, as duas anteriores maiores, todas ântero-dirigidas; frontalia com uma mancha castanho-avermelhada à frente do triângulo ocelar anterior.

Tórax. Escutelo com quatro pares de cerdas negras látero-apicais súpero-dirigidas; anepisterno no terço posterior recoberto de pêlos brancos finos e borda inferior do basilar posterior com cerca de onze cerdas negras agrupadas; catepisterno sem cerdas, somente alguns pêlos brancos longos e raros; anepimero sem cerdas, apenas com pêlos brancos, pouco menores que os do catepisterno, concentrados no disco; catatergito no disco com uma fileira de cerdas brancas com cerca do tamanho do halter, que se continuam no metanepisterno e metacatepisterno onde são mais finas e menores acompanhadas de pêlos brancos (um exemplar com quatro cerdas negras misturadas com as brancas); parede post-alar com um tufo de pêlos amarelados finos e curtos; halter castanho-claro com cabeça de mesma cor. Coxa anterior com cerdas brancas.

Abdome (Figs 4, 9). Coloração geral castanha-avermelhada. Segmentos I com cerdas negras, que variam de duas a cinco, entre pêlos finos e brancos, as cerdas são de mesmo tamanho que o pêlo. Terminália masculina com epândrio afilando abruptamente no 1/3 distal; predominância de cerdas finas; presença de espinhos na margem interior, no $1 / 3$ distal e espinhos menores no $1 / 4$ basal; edeago (Fig. 15) com apódema do edeago com espinhos no ápice e distifalo com espessamento.

Fêmea (Figs 3, 12). Difere do macho pelas seguintes características abaixo.

Anepisterno com cerca de quatro a seis cerdas; segmento I do abômen com cerdas negras maiores que os pêlos brancos.

Espermateca com furca cerca de mesmo tamanho que o ducto capsular (Fig. 12).

Material examinado. E.U.A., Alabama: Sheffield, 1 macho, 06.VI.1942, J. Lane leg. (MZSP); Texas: Dallas (Seagoville), 1 fêmea, IX.1944, Weyrauch leg. (MZSP); Oklahoma: Sallisaw, 1 macho, 24.VI.1934, A.E. Pritchard leg. (MZSP); 
Arizona: 1 fêmea, D.K. Duncan leg. (MZSP); San Carlos, 1 macho, VII, D.K. Duncan leg. (MZSP); Oklahoma: Beaver, 1 fềmea, 28.VII.1933, A.E. Pritchard leg. (MNRJ).

\section{Triorla striola (Fabricius, 1805)}

Figs $5,6,10,13,16$

Dasypogon striola Fabricius, 1805: 172.

Erax maculatus Macquart, 1838: 111. - Macquart, 1839: 232.

Eicherax striola; Carrera \& Machado-Allison, 1963: 254.

Macho difere de Triorla parastriola sp.n. no que se segue.

Cabeça. Calosidade com cerdas negras formando um semi-círculo, cerdas amarelas ântero-dirigidas e mais robustas dispostas em triângulo que terminam no meio do semi-círculo e cerdas brancas menores intercaladas com as amarelas; parafaciália com duas a quatro cerdas negras acompanhadas de outros pêlos e cerdas menores; metade inferior da parafrontália com cerca de duas a cinco cerdas negras acompanhadas de pêlos brancos e negros.

Tórax. Escutelo com seis pares de cerdas negras látero-apicais súpero-dirigidas; anepisterno com cerca de dez cerdas negras agrupadas; catepisterno com pêlos negros e brancos longos; anepímero com pêlos castanhos; catatergito com fileira de cerdas negras que continuam no metanepisterno e metacatepisterno onde são mais finas e menores acompanhadas de pêlos brancos e castanhos; parede pós-alar com um tufo de pêlos negros e finos.

Abdome (Figs 6,10). Segmento I com cerca de três a cinco cerdas negras misturadas entre pêlos finos negros e brancos. Terminália masculina com ápice do epândrio reto distalmente; epândrio afilando gradativamente em direção ao ápice; cerdas grossas e finas distribuídas igualmente; presença de espinhos na margem interior, no quarto distal e espinhos menores no quarto basal; edeago (Fig. 16). Apódema do edeago com espinhos no terço apical e distifalo com espessamento.

Fêmea (Figs 5, 13). Espermateca com furca aproximadamente três vezes menor que o ducto capsular (Fig. 13).

Material examinado. Brasil, Rio Grande do Norte: Natal, 1 macho, VII. 1950, M. Alvarenga leg. (MNRJ); Mato Grosso: B. Tapirapé, 8 fềmeas e 1 macho, 1949, Carvalho leg. (MNRJ); Goiás: Goiânia (Campinas), 1 fêmea, XII.1935, Borgmeier \& S. Lopes leg. (MNRJ); Espirito do Santo: Vitória, 1 fêmea, M. Leitão leg. (MNRJ); Paraná: Campina Grande do Sul, 1 fềmea, II.1966 (MNRJ); Minas Gerais: Serra do Cipó (Santana do Riacho), 5 fềmeas e 13 machos, 10-12.III.1995, Couri, Pamplona, Aires \& Lamas leg. (MNRJ). 


\section{REFERÊNCIAS BIBLIOGRÁFICAS}

ARTIGAS, J.N. 1971. Las estructuras quitinizadas de la spermatheca y funda del pene de los asilidos y su valor sistematico a traves del estudio por taxonomia numerica. Gayana Zool. (18): 1-106.

ARTIGAS, J.N. \& N. PAPAVERO. 1988a. The American Genera of Asilidae (Diptera): Keys for identification with an atlas of female spermathecae and other morphological details. I. Key to the subfamilies and subfamily Leptogastrinae Schiner. Gayana Zool. 52 (1-2): 95-114.

. 1988b. The American Genera of Asilidae (Diptera): Keys for identification with an atlas of female spermathecae and other morphological details. II. Key to the Genera of Dasypogoninae Macquart, with descriptions of new genera and species and new synonymies. Gayana Zool. 52 (3-4): 199-260. . 1988c. The American Genera of Asilidae (Diptera): Keys for identification with an atlas of female spermathecae and other morphological details. IV. Key to the Genera of Laphriinae Macquart (except tribe Atomosiini Hermann), with the descriptions of three new tribes and five new species. Bol. Mus. Paraense Emílio Goeldi, Sér. Zool., 4 (2): 211-256.

Bellard, L. 1861. Saggio di ditterologia messicana. Memorie della Reale Accademia della Scienze di Torino, Parte II: 1-99. 2 pls species and new synonymies.

CARRERA, M. \& C.E. MACHADO-AlLISON. 1963. Contribucion al conocimiento de los Asilidae (Diptera) de Venezuela. Acta. Biol. Venez. 3 (15): 233-267.

FABRICIUS, J.C. 1805. Systema antliatorum secundum ordines, genera, species adiecta synonymis, locis, observationibus, descriptionibus. Brunsvigae, $\mathrm{I}-\mathrm{XIV}+15-372+1+30 \mathrm{p}$.

FISHER, E. M. \& H.A. HESPENHEIDE. 1992. Taxonomy and biology of Central American robber flies with an illustrated key to genera. Oxford, Oxford University Press, Vol. 41, p.611-632.

MACQUART, J. 1834. Historie Naturelle des Insects Diptères (Suite à Buffon). In: N.E. RORET. Collection des suites à Buffon, p.1-578.

1838. Diptères exotiques nouveaux ou peu connus 1 (2): 5-207.

1846. Diptères exotiques nouveaux ou peu connus. Supplément. Mém. Soc. Sci. Agric. Lille 1844: 5-238.

MARTIN, C.H. \& N. PAPAVERO. 1970. A catalogue of the diptera of the Americas South of the United States. São Paulo, Museu de Zoologia, Universidade de São Paulo, Vol. 35b, p. 1-139.

PAPAVERO, N. 1973. Studies of Asilidae (Diptera) systematics and evolution. I. A preliminary classification in subfamilies. Arq. Zool. Univ. São Paulo 23: 217-274.

PARKS, L. 1968. Synopsis of Robberfly Genera allied to Efferia and Eicherax, including a new genus. Pan-Pacific Ent. 44 (3): 171-179.

WALKER, F. 1851. Diptera Insecta Saudersiana, or characters of undescribed insects in the collection of William Wilson Saunders, Esq. 1 (2): 77-156.

. 1860. Characters of undescribed Diptera in the Collection of W.W. Saunders. Trans. ent. Soc. London 2 (2, 5): 268-296.

Recebido em 18.VI.1998; aceito em 15.X.1999. 